\title{
Adsorption Behavior of Polyelectrolyte onto Alumina and Application in Ciprofloxacin Removal
}

\author{
Thi Huong Dao ${ }^{1}$, Ngoc Trung Nguyen ${ }^{1}$, Minh Ngoc Nguyen ${ }^{1}{ }^{\complement}$, Cao Long Ngo ${ }^{2,3}$, \\ Nhu Hai Luong ${ }^{3}$, Duy Binh Le ${ }^{3,4, *}$ and Tien Duc Pham ${ }^{1, *(D)}$ \\ 1 Faculty of Chemistry, University of Science, Vietnam National University, Hanoi, 19 Le Thanh Tong, \\ Hoan Kiem, Hanoi 100000, Vietnam; daothihuong.k56@hus.edu.vn (T.H.D.); \\ nguyenngoctrung_t61@hus.edu.vn (N.T.N.); nmngoc@hus.edu.vn (M.N.N.) \\ 2 Department of Supplies and Warehouse, MPS, Vietnam, 80 Tran Quoc Hoan, Cau Giây, \\ Hanoi 100000, Vietnam; nclong@iams.vast.vn \\ 3 Vietnam Academy of Science and Technology, 18 Hoang Quoc Viet, Cau Giay, Hanoi 100000, Vietnam; \\ luonghai76@htd.vast.vn \\ 4 Institute of Propellant and Explosives, MOD, Vietnam, 192 Duc Giang, Long Bien, Hanoi 100000, Vienam \\ * Correspondence: ldbinh@iams.vast.vn (D.B.L.); tienducpham@hus.edu.vn (T.D.P.); \\ Tel.: +84-243- 825-3503 (T.D.P.); Fax: + 84-243-824-1140 (T.D.P.)
}

Received: 9 June 2020; Accepted: 11 July 2020; Published: 14 July 2020

\begin{abstract}
This study aims to investigate the adsorption behavior of a strong polyelectrolyte poly(styrenesulfonate) (PSS) onto alumina particles. Adsorption of PSS onto positively charged alumina surface increased with increasing ionic strength, indicating that non-electrostatic and electrostatic interaction controlled the adsorption. The removal of an emerging antibiotic ciprofloxacin (CFX) from water environment using PSS-modified alumina (PMA) was also studied. The removal of CFX using PMA was much higher than that using alumina particles without PSS modification in all $\mathrm{pH}$ ranges of $2-11$. The removal of $\mathrm{CFX}$ reached $98 \%$ under the optimum conditions of $\mathrm{pH} 6$, contact time of $120 \mathrm{~min}$, adsorbent dosage of five milligrams per milliliter and ionic strength $10^{4}-\mathrm{M} \mathrm{NaCl}$. The adsorption isotherms of CFX at different salt concentrations fit well with a two-step adsorption model, while the adsorption kinetic fit well with a pseudo-second-order model with a good correlation coefficient $\left(\mathrm{R}^{2}>0.9969\right)$. The CFX-removal from a hospital wastewater using PMA was more than $75 \%$. Our study demonstrates that adsorption of PSS onto alumina to modify the particle surface is important to form a novel adsorbent PMA for CFX-removal from water environments.
\end{abstract}

Keywords: PSS; alumina; adsorption isotherm; surface modification; ciprofloxacin

\section{Introduction}

As versatile macromolecular materials, polymers are widely use in different applications such as biotechnology, drug delivery system, biosensor devices, cosmetics and environmental engineering, etc [1-3]. Polyelectrolytes are charged polymers that are often used for material modification in numerous applications including drug delivery [4] and wastewater treatment [5,6]. Therefore, polyelectrolyte adsorption onto solid surfaces is an important subject that is attracting the attention of many scientists.

Antibiotic resistance has become a serious problem across the globe in this century [7,8]. Antibiotic resistance is growing rapidly-especially in developing countries. One reason for the spread of antibiotic resistance is antibiotic residues in wastewater environment $[9,10]$. Therefore, a solution to reduce antibiotic resistance by removing antibiotics from aqueous solutions is of great importance. There are many methods have been investigated to treat antibiotics based on biologic, chemical, and physical processes or combined these techniques [11]. 
The enhancement of water quality is necessary in modem life which is based on applied science and technologies such as chemical [12], biologic [13], physical properties or combined together [14]. Many studies report the different techniques for antibiotic removal such as membrane processes, Fenton oxidation [15], photocatalytic degradation [16] and adsorption, etc. It has been found that adsorption is known as one of most effective methods for organic pollutants removal. In this, the modified adsorbent is an excellent candidate to obtain the high removal of charged molecules like antibiotics $[17,18]$. A novel adsorbent based on polyelectrolyte modified metal oxide particle for antibiotic removal is still a big challenge due the complicated adsorption behavior of antibiotic and adsorbent. The modification of metal oxide with an oppositely charged polyelectrolyte molecules can change the charging behavior of adsorbent and therefore enhance the removal of antibiotic.

To the best of our knowledge, this is the first study that investigates the adsorption of strong polyelectrolyte poly(styrenesulfonate) (PSS) onto alumina to fabricate a high performance adsorbent for removal of an antibiotic ciprofloxacin (CFX) from aqueous solution. The removal of CFX using PSS-modified alumina (PMA) at different conditions such as $\mathrm{pH}$ solution, adsorption time, adsorbent dosage and ionic strength is systematically studied. The application of PMA for CFX-removal from a real wastewater sample collected from hospital is also studied in this work.

\section{Materials and Methods}

\subsection{Materials}

High-purity $(99.99 \%) \alpha-\mathrm{Al}_{2} \mathrm{O}_{3}$ particles with particle size of about $300 \mathrm{~nm}$ were purchased from AKP-30, Sumitomo, Japan. Poly(sodium 4-styrenesulfonate) (PSS)—with a molecular weight of $1000 \mathrm{~kg} / \mathrm{mol}$ - was supplied by Sigma-Aldrich, Singapore. Ciprofloxacin (CFX) in the form of hydrochloride monohydrate (CAS 86393-32-0) > 98\% (HPLC grade) was supplied from Tokyo Chemical Industry (Tokyo, Japan). Other chemicals- analytical-grade $\mathrm{NaCl}, \mathrm{HCl}$ and $\mathrm{NaOH}$ - were delivered from Merck (Darmstadt, Germany). $\mathrm{NaCl}$ was used as ionic content in solution; $\mathrm{HCl}, \mathrm{NaOH}$ were used to adjust the $\mathrm{pH}$ of the solutions. The alumina was treated following previous research [19]. Treated $\alpha-\mathrm{Al}_{2} \mathrm{O}_{3}$ was added with different PSS-concentrations at $\mathrm{pH}$. Then the suspensions were shaken for $2 \mathrm{~h}$ to modify the $\alpha-\mathrm{Al}_{2} \mathrm{O}_{3}$ surface [19].

\subsection{Adsorption Studies}

The adsorption of PSS onto $\alpha-\mathrm{Al}_{2} \mathrm{O}_{3}$ particles is detailed in our previous study [19]. The optimum conditions for PSS adsorption were adsorption time $120 \mathrm{~min}$, mass ratio of PSS to alumina $20 \mathrm{mg} / \mathrm{g}$ and $\mathrm{pH} 4$, using the batch-adsorption technique. The change in FT-IR results and the zeta potential confirmed the appearance of PSS onto $\alpha-\mathrm{Al}_{2} \mathrm{O}_{3}$ [19]. In this research, the adsorption isotherms at different ionic strength were conducted and modeled by two-step adsorption model. The PSS-modified $\alpha-\mathrm{Al}_{2} \mathrm{O}_{3}$ at optimum conditions is called PMA. The PSS solutions were separated using a refrigerated centrifuge (MR23i, JOUAN, France) with the speed of 12,000 rpm $\left(5^{\circ} \mathrm{C}\right)$ for $10 \mathrm{~min}$. Concentrations of PSS were determined by molecular spectroscopy (UV-Vis). The adsorption capacity $\Gamma$ (mg/g) of PSS or CFX onto $\alpha-\mathrm{Al}_{2} \mathrm{O}_{3}$ or PMA was calculated by Equation (1):

$$
\Gamma=\frac{C_{i}-C_{f}}{m}
$$

where $C_{i}(\mathrm{mg} / \mathrm{L})$ is the initial concentration of PSS or CFX, $C_{f}(\mathrm{mg} / \mathrm{L})$ are the final concentrations of PSS or CFX and $m(\mathrm{mg} / \mathrm{mL})$ is the adsorbent dosage.

For CFX adsorption, a stock solution of CFX was prepared by dissolved an accurate amount of CFX salt into $100 \mathrm{~mL}$ of ultrapure water to form a solution of $1000 \mathrm{mg} / \mathrm{L}$. Each day, the working solution was diluted from the stock solution. The adsorption of $\mathrm{CFX}$ with $\alpha-\mathrm{Al}_{2} \mathrm{O}_{3}$ or PMA was conducted by batch technique using an orbital shaker (OS-350D, Digisystem, Taipei, Taiwan) at room temperature $25 \pm 2{ }^{\circ} \mathrm{C}$, controlling by air-conditioned laboratory. 
The removal (\% R) of CFX was determined by Equation (2):

$$
\text { Removal }(\% R)=\frac{C_{i}-C_{e}}{C_{i}} \times 100 \%
$$

where $\mathrm{Ci}$ and $\mathrm{Ce}$ are initial concentration and equilibrium concentration of CFX (mg/L), respectively. The experimental adsorption studies were carried out in triplicate and are shown with standard deviation error.

\subsection{Analysis and Characterization}

Spectrophotometry was used to determine concentration of PSS and CFX. The concentrations of PSS and CFX were calculated from linear relationship of absorbance and concentration of PSS and CFX by using a spectrophotometer (UV-1650 PC, Shimadzu, Kyoto, Japan) with a double of 10-mm path length quart cuvettes and the wavelength of 263 and $277 \mathrm{~nm}$ for PSS and CFX, respectively [20,21].

The surface functional groups of the materials were evaluated by Fourier-transform infrared spectroscopy FT-IR using an Affinity-1S spectrometer (Shimadzu, Japan). The change in functional groups in FT-IR spectra was used for confirmation of PSS onto $\alpha-\mathrm{Al}_{2} \mathrm{O}_{3}$.

\subsection{Modeling by General Isotherm Equation}

A general isothermal equation was used to fit adsorption isotherms of both PSS and CFX onto adsorbents. A two-step adsorption assumes that the adsorption follows two steps at the solid-liquid interface [22]. The equation is shown below:

$$
\Gamma=\frac{\Gamma_{\infty} k_{1} C\left(\frac{1}{n}+k_{2} C^{n-1}\right)}{1+k_{1} C\left(1+k_{2} C^{n-1}\right)}
$$

where $\Gamma$ is the adsorbed amount of CFX/PSS, C denotes the equilibrium concentrations of CFX/PSS in solution, $\mathrm{k}_{1}$ and $\mathrm{k}_{2}$ are equilibrium constants for the first layer adsorption and clusters of $\mathrm{n}$ molecules or multilayer adsorption and $\Gamma_{\infty}$ is the maximum adsorbed amount $n$.

The selected fitting parameters are described in our previously published papers [23-25].

\subsection{Adsorption Kinetic}

Pseudo-first-order and pseudo-second-order models were employed to evaluate the kinetic reaction order. The pseudo- first-order model is

$$
\log \left(q_{e}-q_{t}\right)=\log q_{e}-\frac{K_{1, k}}{2.303} t
$$

where $\mathrm{q}_{\mathrm{e}}$ is the maximum adsorption capacity, $\mathrm{q}_{\mathrm{t}}$ is the equilibrium adsorption capacity at the time $\mathrm{t}$, $K_{1, k}$ is pseudo-first-order rate constant and $t$ is adsorption contact time. The approximate minimum sum of square was applied for fitting model.

The pseudo-second-kinetic-order model was written as the equation:

$$
\frac{t}{q_{t}}=\frac{1}{K_{2, k} \cdot q_{e}^{2}}+\frac{1}{q_{e}} t
$$

where $K_{2, \mathrm{k}}$ is the pseudo-second-order rate constant. The pseudo-second-order model directly fit the experiment results with the interaction of valence force of solute and adsorbent. 


\section{Results and Discussion}

\subsection{Adsorption of PSS onto $\alpha-\mathrm{Al}_{2} \mathrm{O}_{3}$}

The surface modification of PSS onto $\alpha-\mathrm{Al}_{2} \mathrm{O}_{3}$ was studied in our previous publication [19]. In this research, the adsorption isotherms of PSS at two $\mathrm{NaCl}$ concentrations ( $\mathrm{pH} 4)$ onto $\alpha-\mathrm{Al}_{2} \mathrm{O}_{3}$ are shown in Figure 1. As can be seen in Figure 1, the PSS adsorption isotherms onto $\mathrm{Al}_{2} \mathrm{O}_{3}$ fit very well by the two-step adsorption model with the fit parameters shown in Table 1.

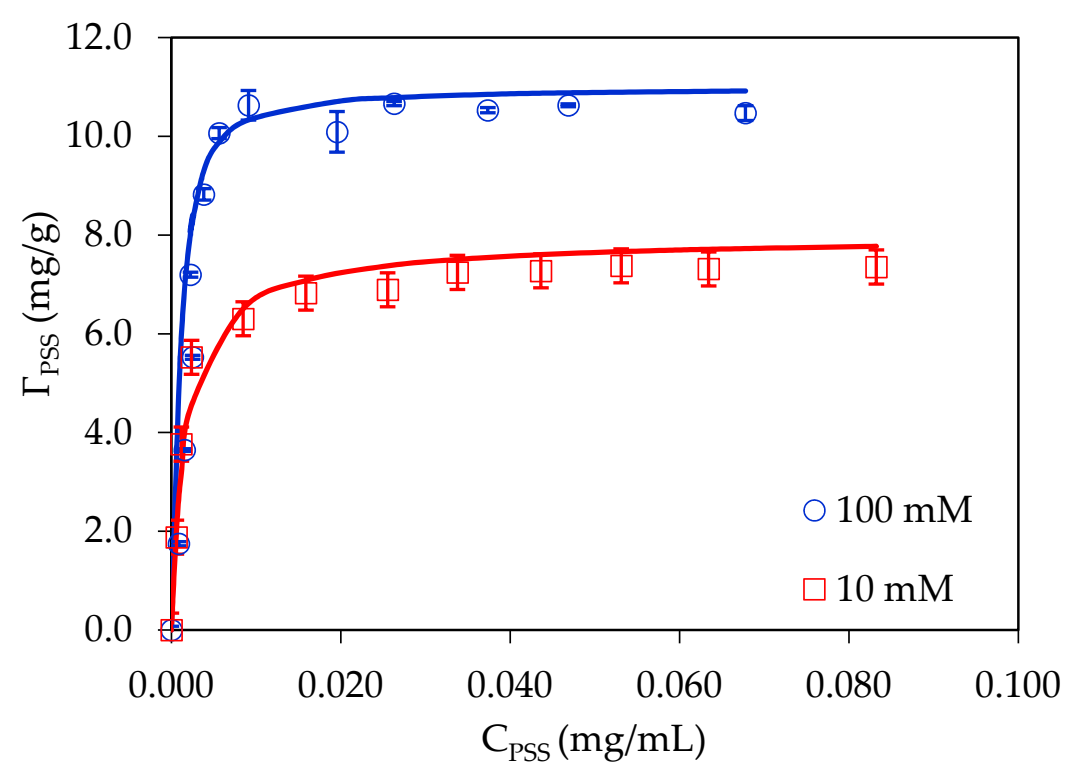

Figure 1. Adsorption isotherms of poly(styrenesulfonate) (PSS) onto $\alpha-\mathrm{Al}_{2} \mathrm{O}_{3}$ at two $\mathrm{NaCl}$ concentrations ( $\mathrm{pH} \mathrm{4}$, adsorption time $120 \mathrm{~min}$, mass ratio of PSS to alumina $20 \mathrm{mg} / \mathrm{g}$ ). Points are experimental data while solid lines are the results of the two-step adsorption model. Error bars show standard deviations of three replicate.

Table 1. Fit parameters for the adsorption isotherms onto $\mathrm{Al}_{2} \mathrm{O}_{3}$ at different $\mathrm{NaCl}$ concentration $(\mathrm{pH}$ 4). The maximum adsorbed amount $\Gamma_{\infty, \mathrm{PSS}}$, the equilibrium constants $k_{1, \mathrm{PSS}}, k_{2, \mathrm{PSS}}$ for first layer and multilayer, respectively, $n$ the number of clusters of PSS molecules.

\begin{tabular}{ccccc}
\hline $\mathrm{C}_{\mathrm{NaCl}}(\mathrm{mM})$ & $\Gamma_{\infty, \mathrm{PSS}}(\mathrm{mg} / \mathrm{g})$ & $\boldsymbol{k}_{\mathbf{1}, \mathrm{PSS}}(\mathrm{g} / \mathbf{m g})$ & $k_{2, \mathrm{PSS}}(\mathrm{g} / \mathbf{m g})^{\mathbf{n}-1}$ & $n_{\mathrm{PSS}}$ \\
\hline 100 & 11.0 & 900 & 1000 & 1.9 \\
10 & 8.0 & 1000 & 150 & 1.9 \\
\hline
\end{tabular}

Figure 1 shows that adsorbed amount of PSS onto $\alpha-\mathrm{Al}_{2} \mathrm{O}_{3}$ increased with increasing $\mathrm{NaCl}$ concentration from 10 to $100 \mathrm{mM}$. It is also observed that the adsorption amount of PSS onto $\mathrm{Al}_{2} \mathrm{O}_{3}$ at $100-\mathrm{mM} \mathrm{NaCl}$ was always higher than that at $10-\mathrm{mM} \mathrm{NaCl}$. At high salt concentrations, the number of anions $\mathrm{Cl}^{-}$(counter ions) increased, thus the electrostatic attraction between positively charged alumina surface and polyanion decreased [26]. Nevertheless, non-electrostatic interactions such as hydrophobic interaction, hydrogen bonding and Van der Waals forces-as well as the lateral interaction between PSS molecules may contribute to adsorption [27]. It should be noted that an increase of ionic strength may induce the $R_{\mathrm{h}}$ change of polyelectrolyte. For PSS, the $R_{\mathrm{h}}$ increased from 11.7 to $13.8 \mathrm{~nm}$ with an increase of ionic strength from 1 to $150 \mathrm{mM}$ [28]. Polyelectrolyte adsorption at high ionic strengths may produce many counter ions to the bulk solution-thus the driving force for adsorption may be influenced by increasing entropy $[29,30]$.

Table 1 and Figure 1 also indicate that at $10-\mathrm{mM} \mathrm{NaCl}$, the maximum adsorbed amount of PSS $\left(\Gamma_{\infty}\right)$ for $\alpha-\mathrm{Al}_{2} \mathrm{O}_{3}$ was $8.0 \mathrm{mg} / \mathrm{g}$, while at $100-\mathrm{mM} \mathrm{NaCl}$ this value increased to $11.0 \mathrm{mg} / \mathrm{g}$. This implies that, at high salt concentration the lateral and hydrophobic interactions may induce more loops and 
tails in the structure of adsorbed PSS onto $\mathrm{Al}_{2} \mathrm{O}_{3}$. As a result, the values of $k_{2, \text { PSS }}$ were much higher at high salt compared with that at low salt. On one hand, the values of $k_{1}$ (denoting for first layer adsorption) did not significantly change. Therefore, the PSS-adsorbed layer was less flat at higher salt concentrations than that at low salt concentrations. As the resulted, PSS adsorption capacity increased with an increase of salt concentration. The results here are similar to polyelectrolyte adsorption onto cotton fiber, in which adsorption with a high value of $k_{2}$ with a multilayer formation were found [31].

Figure 2 shows the FTIR spectra of $\mathrm{Al}_{2} \mathrm{O}_{3}$ before and after PSS adsorption The asymmetric and symmetric bands of PSS at 1185 and $1039 \mathrm{~cm}^{-1}$ [32], did not appear at the FT-IR of $\mathrm{Al}_{2} \mathrm{O}_{3}$ while a small symmetric band of $1039 \mathrm{~cm}^{-1}$ shifted to longer wavenumber of $1130 \mathrm{~cm}^{-1}$ on the surface of $\mathrm{Al}_{2} \mathrm{O}_{3}$ after PSS adsorption. Furthermore, the stretching of C-S groups in PSS molecules at $676 \mathrm{~cm}^{-1}$ and the boarding peaks at about $3550 \mathrm{~cm}^{-1}$ assigned for $\mathrm{O}-\mathrm{H}$ [33], changed to the various peaks at the wavenumber of $3400-3600 \mathrm{~cm}^{-1}$ in FT-IR spectra of $\mathrm{Al}_{2} \mathrm{O}_{3}$ after PSS adsorption. This suggests that hydrogen bonding, lateral interaction and electrostatic attraction may contribute to the PSS adsorption onto $\alpha-\mathrm{Al}_{2} \mathrm{O}_{3}$.

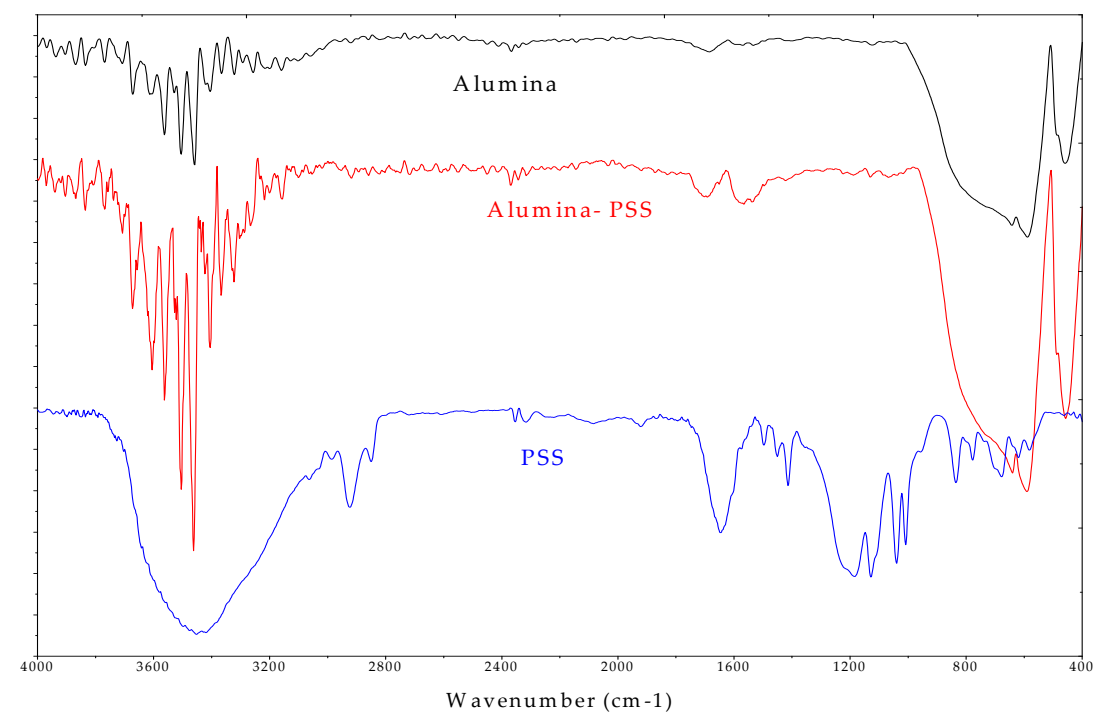

Figure 2. FT-IR spectra of alumina and alumina modified with PSS (alumina-PSS) and PSS.

The results of adsorption isotherm and FT-IR spectra indicate that the PSS adsorption onto $\alpha-\mathrm{Al}_{2} \mathrm{O}_{3}$ surface achieved the maximum adsorption amount of $11 \mathrm{mg} / \mathrm{g}$ at $100-\mathrm{mM} \mathrm{NaCl}$, contact time $120 \mathrm{~min}$ and $\mathrm{pH} 4$, as shown in our previous publication [19]. The PMA was formed with the initial PSS concentration of $0.1 \mathrm{mg} / \mathrm{mL}$.

\subsection{Optimization of Effective Parameters for CFX-Removal}

\subsubsection{Effect of $\mathrm{pH}$ on CFX-Removal Using $\alpha-\mathrm{Al}_{2} \mathrm{O}_{3}$ and PSS-Modified $\alpha-\mathrm{Al}_{2} \mathrm{O}_{3}$ (PMA)}

The effect of $\mathrm{pH}$ on CFX-removal using $\alpha-\mathrm{Al}_{2} \mathrm{O}_{3}$ and PSS-modified $\alpha-\mathrm{Al}_{2} \mathrm{O}_{3}$ (PMA) is shown in Figure 3. As can be seen, the highest removed CFX efficiency was achieved at $\mathrm{pH} 6$, which was about $98 \%$ when using PMA. On one hand, at low $\mathrm{pH}$, the $\alpha-\mathrm{Al}_{2} \mathrm{O}_{3}$ may have been dissolved, so that the removal of CFX decreased. On the other hand, under basic conditions, the CFX formed the negative species that induced the repulsive electrical force between adsorbent and CFX. Furthermore, the desorption of PSS out to PMA may occur at high $\mathrm{pH}$. Figure 3 shows the $\mathrm{pH}$ optimum for CFX-removal is 6.0 which is closed to $p K_{\mathrm{a} 1}$ of $\mathrm{CFX}$ [34]. Figure 3 also indicate that CFX-removal using $\alpha-\mathrm{Al}_{2} \mathrm{O}_{3}$ was extremely low efficiency compared with PMA at all $\mathrm{pH}$ range. The highest CFX-removal at pH 7 was only $40 \%$, while the maximum CFX using PMA removal reached to $98 \%$. This implies that PMA was much better adsorbent than raw $\alpha-\mathrm{Al}_{2} \mathrm{O}_{3}$ for $\mathrm{CFX}$-removal. 


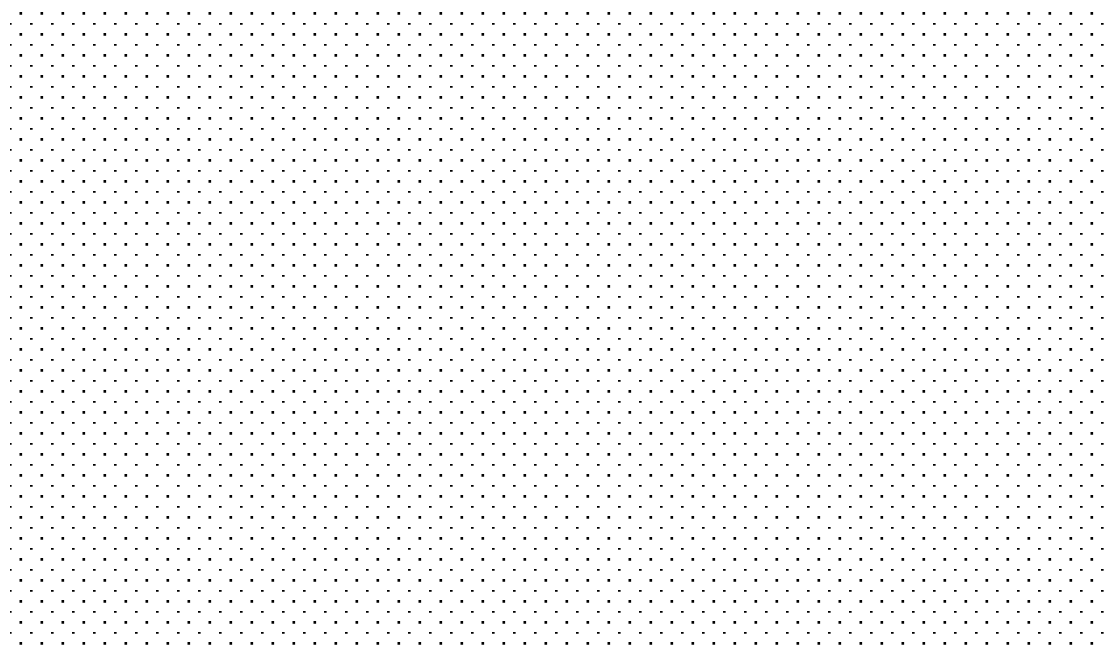

O modified alumina

$\square$ non modified alumina

Figure 3. Effect of $\mathrm{pH}$ on ciprofloxacin (CFX) removal using $\alpha-\mathrm{Al}_{2} \mathrm{O}_{3}$ (non-modified alumina) and PMA (modified $\mathrm{Al}_{2} \mathrm{O}_{3}$ ) from $\mathrm{pH} 2$ to 10 . ( $\mathrm{Ci}(\mathrm{CFX})=10 \mathrm{mg} / \mathrm{L}$, contact time $90 \mathrm{~min}$, adsorbent dosage $5 \mathrm{mg} / \mathrm{mL}, 1-\mathrm{mM} \mathrm{NaCl}$ ). Error bars show standard deviation of three replicates.

\subsubsection{Effect of Ionic Strength on CFX-Removal Using $\alpha-\mathrm{Al}_{2} \mathrm{O}_{3}$ and PMA}

Ionic strength can influence to electrostatic interactions [22]. CFX-removal using $\alpha-\mathrm{Al}_{2} \mathrm{O}_{3}$ and PMA was conducted at $\mathrm{pH} 6$, adsorbent dosage $5 \mathrm{mg} / \mathrm{mL}$ and contact time $90 \mathrm{~min}$-with different ionic strength from 0 - to $100-\mathrm{mM} \mathrm{NaCl}$.

Figure 4 shows that an increase of $\mathrm{NaCl}$ concentration induced a decrease of $\mathrm{CFX}$-removal. At high salt concentrations, the electrostatic attraction was screened while the removal of CFX decreased due to the decrease of electrostatic interaction. The effect of ionic strength for the cases of non-modified alumina and modified alumina showed similar trends. At different ionic strengths, CFX-removal using PMA was much higher than that using non-modified alumina. Therefore, further studies focus only on the PMA, which was better than $\alpha-\mathrm{Al}_{2} \mathrm{O}_{3}$ without PSS.

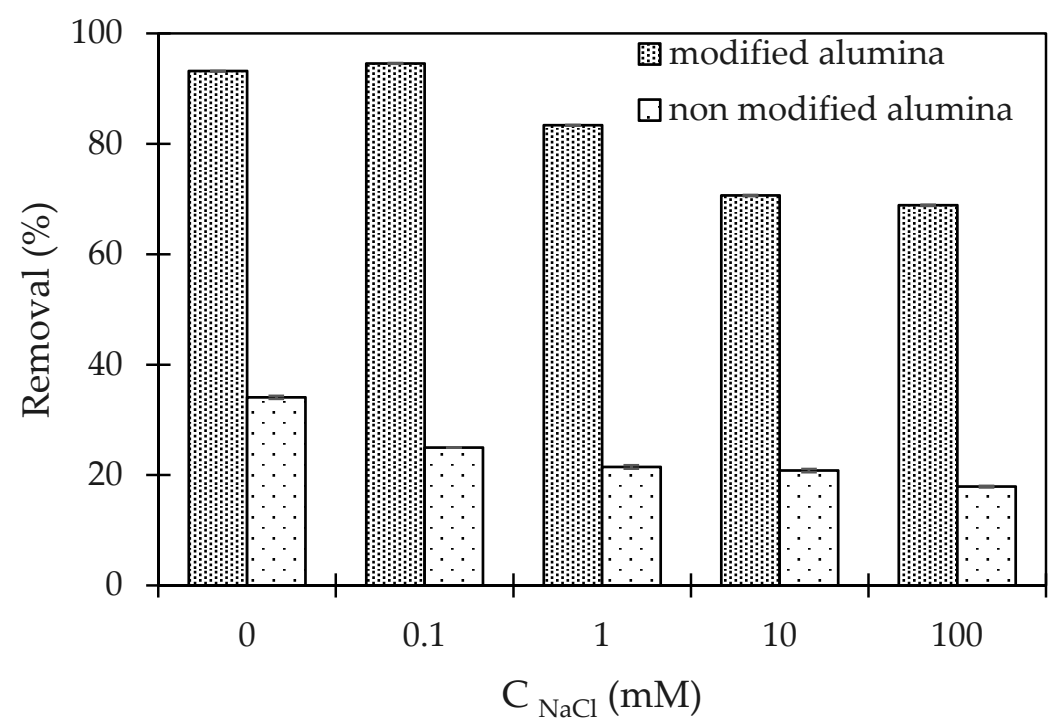

Figure 4. Effect of ionic-strength $\mathrm{CFX}$-removal using $\alpha$-Al2O3 (non-modified alumina) and PMA (modified alumina). (Ci (CFX) = $10 \mathrm{mg} / \mathrm{L}$, contact time $90 \mathrm{~min}$, adsorbent dosage $5 \mathrm{mg} / \mathrm{mL}$, $\mathrm{pH}$ 6). Error bars show standard deviation of three replicates. 


\subsubsection{Effect of Contact Time on CFX-Removal Using PMA}

The time to achieve the equilibrium for CFX adsorption process is known as the contact time. The effect of contact time for CFX-removal with the different time intervals is shown in Figure 5.

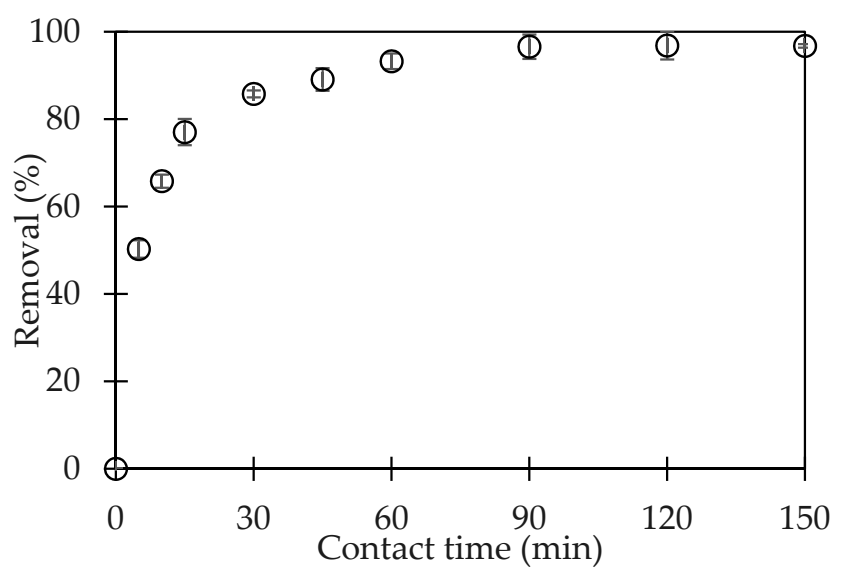

Figure 5. Effect of contact time on CFX-removal by using PSS-modified alumina (PMA). (Ci (CFX) $=10 \mathrm{mg} / \mathrm{L}$, adsorbent dosage $5 \mathrm{mg} / \mathrm{mL}, \mathrm{pH}$ 6, 1-mM NaCl). Error bars show standard deviation of three replicates.

As shown in Figure 5, CFX-removal increased with an increase of contact time from 0 to 90 min. After 90 min shaking, CFX-adsorption onto PMA reached an equilibrium with about $97 \%$ of CFX-removal. Thus, the CFX-adsorption onto PMA could reach saturation after $90 \mathrm{~min}$. After this, CFX-removal changed insignificantly. The contact time of $90 \mathrm{~min}$ was much shorter than other materials in previously published papers [34,35]. Therefore, the optimum contact time for CFX-removal using PMA is 90 min that was kept for the next studies on CFX-removal using PMA.

\subsubsection{Effect of Adsorption Dosage on CFX-Removal Using PMA}

The adsorbent dosage is important parameter which strongly influences to the total surface area and surface-charge density. The result of ionic strength effect suggests that the main interaction in CFX-adsorption onto PMA is electrostatic attraction, which is depended on charge density. Various adsorbent dosages of PMA ranging from 0.1 to $15-\mathrm{mg} / \mathrm{mL}$ were used to remove CFX. The results are indicated in Figure 6.

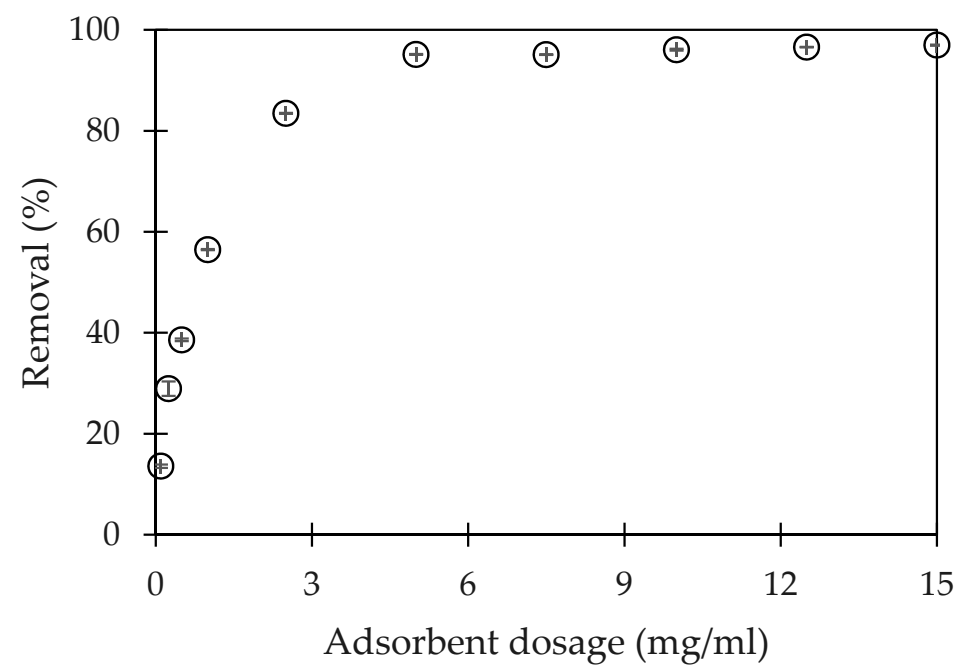

Figure 6. Effect of adsorbent dosage on CFX-removal by using PMA. (Ci (CFX) $=10 \mathrm{mg} / \mathrm{L}$, contact time $90 \mathrm{~min}, \mathrm{pH}$ 6, 1-mM NaCl). Error bars show standard deviation of three replicates. 
Figure 6 shows that CFX-removal increased significantly with the 0.1 to $5-\mathrm{mg} / \mathrm{mL}$ adsorbent dosage. Then, CFX-removal remained stable with increasing adsorbent dosage. The total surface area and charge density increased with increasing adsorption dosage. However, CFX-removal did not increase for a larger amount of adsorbent dosage of greater than $5 \mathrm{mg} / \mathrm{mL}$ due to the fact that CFX-adsorption amount onto the PMA surface was saturated. Therefore, the optimum adsorbent dosage for CFX-removal using PMA was $5 \mathrm{mg} / \mathrm{mL}$.

\subsection{Adsorption Isotherms of CFX onto PMA}

The effect of ionic strength onto CFX-adsorption with various initial concentrations was clearly observed on the isotherms (Figure 7). Adsorption isotherms show the effects of ionic strength and initial concentration. Figure 7 shows the adsorption capacity as the function of CFX concentrations from 5 to $800 \mathrm{mg} / \mathrm{L}$ at $0.1-, 1$ - and $10-\mathrm{mM} \mathrm{NaCl}$ under the optimum conditions of $\mathrm{pH}$ 6, contact time $90 \mathrm{~min}$ and adsorbent dosage of $5 \mathrm{mg} / \mathrm{mL}$.

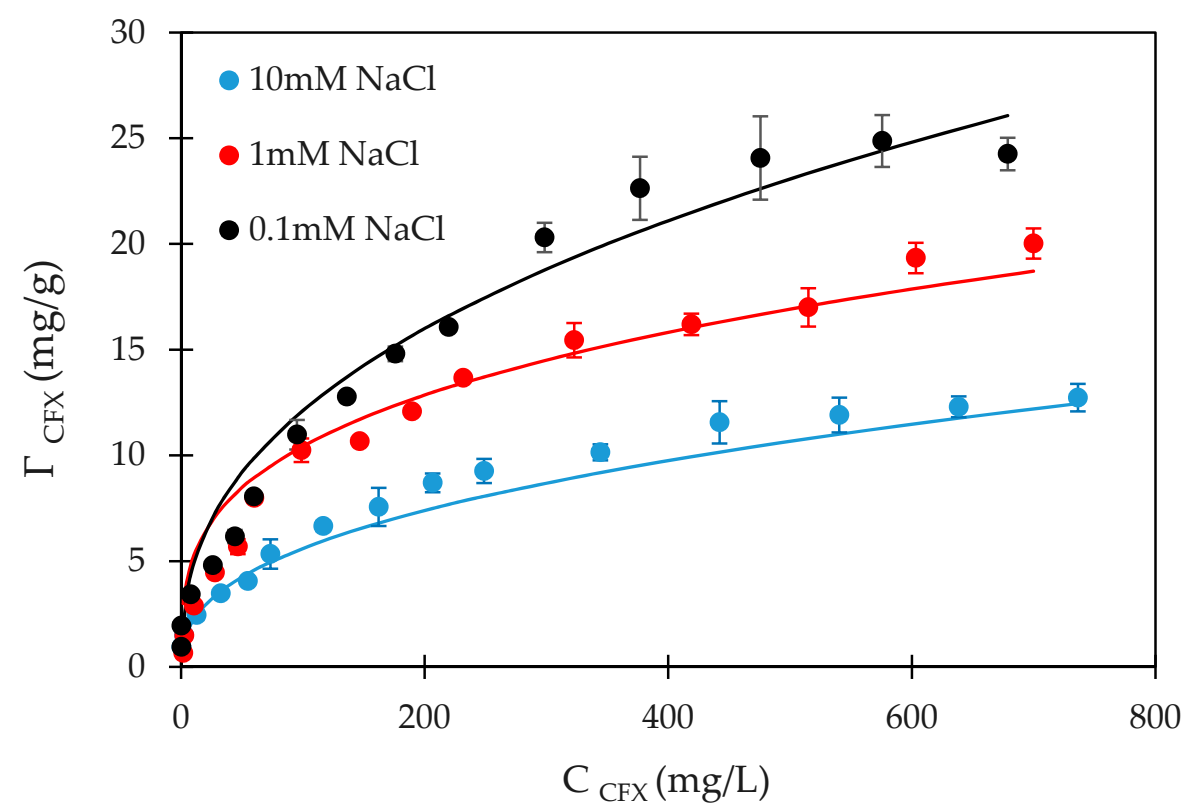

Figure 7. Adsorption isotherms of CFX onto PMA at different $\mathrm{NaCl}$ concentrations. Points are experimental results while solid lines are fitted by the two-step adsorption model. Error bars show standard deviation of three replicates.

As discussed in the section on the effect of ionic strength, the CFX-removal decreased with increasing $\mathrm{NaCl}$ concentration with a low CFX concentration of $10 \mathrm{mg} / \mathrm{L}$. Herein, the adsorption isotherms with different initial CFX concentrations achieved the similar trend. The adsorption of CFX onto PMA reduced with an increase of ionic strength. The high ionic strength caused the increase in the number of positive cations (counter ions) and decrease of the electrostatic attraction between cationic species CFX and negatively charged PMA surface. The counter ions $\mathrm{Na}^{+}$in the solution caused the electrical double layer decreased so that the net charge of PMA was decreased [36]. Other interactions such as hydrophobic interaction, Van der Waals and hydrogen bonding known as non-electrostatic ones could induce the adsorption at high salt concentration. However, the adsorption capacity of CFX at high salt was much smaller than that at low salt, representing that the adsorption isotherm at low salt was always above the isotherm at high salt. This indicates that CFX-adsorption onto PMA is induced by electrostatic attraction rather than non-electrostatic interactions.

Figure 7 also indicates that the experimental data fit well with the two-step adsorption model using the fit parameters shown in Table 2. The CFX-adsorption isotherms onto PMA was fitted well by a two-step model. The values of $k 1$ were obtained from adsorption at low concentrations of CFX 
by applying the Langmuir equation. The variables of $k_{2}$ and $n$ were determined by trials and error

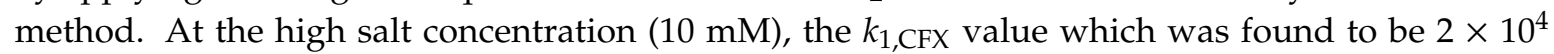
$\left(\mathrm{g} / \mathrm{mg}^{-1}\right)$ was11 times greater than that at low salt concentration $(0.1 \mathrm{mM})$. It implies that the active sites for adsorption of CFX increased with decreasing salt concentration. In other words, the higher value of $k_{1, \mathrm{CFX}}$ obtained, the stronger was the electrostatic attraction induced CFX-adsorption. The maximum adsorption capacity at $0.1 \mathrm{mM}$ was 2 times higher than that at $10-\mathrm{mM} \mathrm{NaCl}$. The $n_{\mathrm{CFX}}$ was the same while the value of $k_{2, \mathrm{CFX}}$ changed insignificantly for all cases. The error bars shown the standard deviations of different replicates were reasonable and close to solid line, indicating that the model was suitable to represent adsorption isotherm of CFX onto PMA. Based on the fitting parameters, it can be found that the CFX-adsorption occurred onto PMA surface by a monolayer than the multilayer formation that is similar trends in previous publications [36-38].

Table 2. Fit parameters for the adsorption isotherms of CFX onto PSS-modified $\mathrm{Al}_{2} \mathrm{O}_{3}$ (PMA) at different $\mathrm{NaCl}$ concentrations ( $\mathrm{pH}$ 6). The maximum adsorbed amount is $\Gamma_{\infty}$, PSS, the equilibrium constants are $k_{1, \mathrm{CFX}}, k_{2, \mathrm{CFX}}$ for first layer and multilayer, respectively, $n$ the number of clusters of CFX molecules.

\begin{tabular}{ccccc}
\hline $\mathrm{C}_{\mathrm{NaCl}}(\mathbf{m M})$ & $\Gamma_{\infty, \mathrm{PSS}}(\mathbf{m g} / \mathbf{g})$ & $k_{\mathbf{1 , C F X}}\left(\mathbf{1 0}^{\mathbf{4}} \mathbf{g} / \mathbf{m g}\right)$ & $k_{2, \mathrm{CFX}}(\mathrm{g} / \mathbf{m g})^{\mathbf{n}-1}$ & $n_{\mathrm{CFX}}$ \\
\hline 0.1 & 28.02 & 22 & 1260 & 1.4 \\
1 & 19.92 & 9 & 1249 & 1.4 \\
10 & 13.02 & 2 & 1250 & 1.4 \\
\hline
\end{tabular}

\subsection{Adsorption Kinetic of CFX onto PMA}

The CFX-kinetic adsorption onto PMA was studied with three different CFX initial concentrations of $10,50,250 \mathrm{mg} / \mathrm{L}$, under the optimum adsorption conditions.

Table 3 shows the rate constant $(K)$, adsorption capacity $\left(q_{\mathrm{e}}\right)$ and correlation coefficients $\left(R^{2}\right)$ of the pseudo-first-order and pseudo-second-order models. The effectiveness of model was evaluated through the $R^{2}$ values. As can be seen, the pseudo-second-order model fit the adsorption kinetic of CFX better than the pseudo-first-order one, indicating that the adsorption kinetic of CFX onto PMA is in accordance with pseudo-second-order. The linear fits based on the experimental data are shown in Figure 8.

Table 3. Parameters of adsorption kinetics of ciprofloxacin (CFX) onto PMA.

\begin{tabular}{|c|c|c|c|c|c|c|}
\hline \multirow{2}{*}{$C \mathbf{i}(\mathrm{mg} / \mathrm{L})$} & \multicolumn{3}{|c|}{ Pseudo-First-Order } & \multicolumn{3}{|c|}{ Pseudo-Second-Order } \\
\hline & $K_{1, \mathrm{k}}(1 / \mathrm{min})$ & $q_{\mathrm{e}}(\mathrm{mg} / \mathrm{g})$ & $R^{2}$ & $K_{2, \mathrm{k}}$ (g/mg.min) & $q_{\mathrm{e}}(\mathrm{mg} / \mathrm{g})$ & $R^{2}$ \\
\hline 10 & 0.146 & 1.835 & 0.9863 & 0.225 & 1.904 & 0.9990 \\
\hline 50 & 0.131 & 4.879 & 0.9984 & 0.106 & 4.930 & 0.9991 \\
\hline 250 & 0.124 & 13.865 & 0.9686 & 0.014 & 14.992 & 0.9969 \\
\hline
\end{tabular}

Figure 8 shows that adsorption kinetics of CFX onto PMA at three initial CFX concentrations fitted by pseudo-second-order achieved high $\mathrm{R}^{2}$ values (>0.9969). The value of $\mathrm{K}_{2}$ decreased from 0.225 to 0.014 when the initial CFX concentrations increased from 10 to $250 \mathrm{mg} / \mathrm{L}$. The decrease in the adsorption rate constant represents the adsorption kinetics for higher initial concentration of CFX because of limited number of adsorption sites of PMA. Our results here are similar to adsorption of organic molecules onto surface modified adsorbents [17,19,25,36]. 


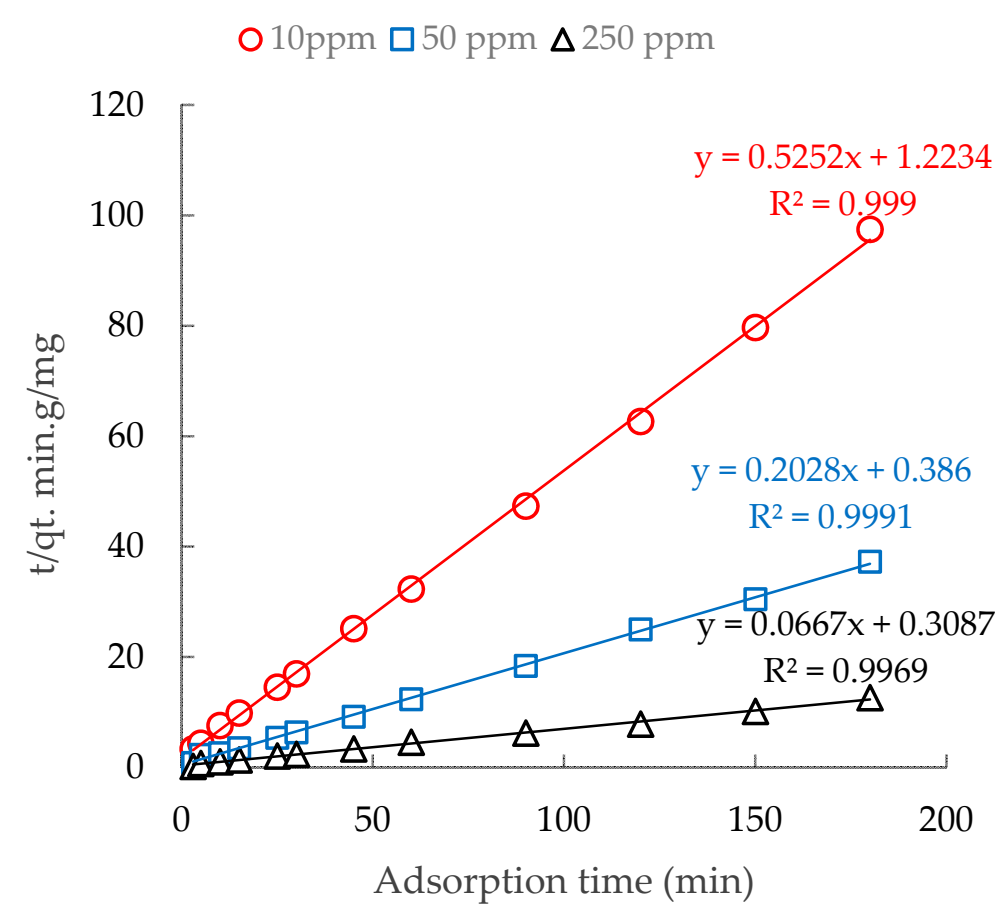

Figure 8. Pseudo-second-order model for CFX-adsorption kinetic onto PMA with three initial CFX concentrations.

\subsection{Regeneration Study}

The regeneration of adsorbent is a key role to evaluate the stability and reusable property. The various type of desorption solutions including $0.1-\mathrm{M} \mathrm{NaOH}, 0.1-\mathrm{M} \mathrm{HCl}$ and methanol $(\mathrm{MeOH})$ were used to conduct the desorption process. Almost CFX could desorb using $\mathrm{NaOH}$ one time then it is decreased rapidly with the next desorption. The desorption when using $\mathrm{HCl}$ was about $50 \%$ then it decreased slightly with the more desorption time. On the other hand, CFX could not desorb when using $\mathrm{MeOH}$ (not shown in detail).

PMA after desorption was used to conduct CFX-removal again to evaluate the generation potential of the adsorbent (Figure 9). Figure 9 shows that the CFX-removal after regeneration still reached greater than $80 \%$, and it changed insignificantly after three times of reuse. For $\mathrm{NaOH}$, the CFX-removal slightly decreased after reuse of the adsorbent. The results show that PSS desorption could be occurred simultaneously with CFX desorption. When using $\mathrm{MeOH}, \mathrm{CFX}$-removal decreased too much at the third time of CFX-removal. The $\mathrm{MeOH}$ solution cannot be used for CFX desorption that may be explained by the unsaturated adsorption of modified PMA. Because CFX-adsorption occurs on the positively charged PMA surface, the highest desorption will take place with a basic solution. On one hand, $\mathrm{HCl}$ can produce negatively charged ions $\left(\mathrm{Cl}^{-}\right)$, so that a competition of adsorption occurs that can promote the CFX-adsorption. On the other hand, the interaction of $\mathrm{MeOH}$ with $\mathrm{CFX}$ on the adsorbent is hydrophobic interaction that is not strong enough to desorb the CFX from the adsorbent. The generation study indicate that the PMA is reusable adsorbent for CFX-adsorption. 

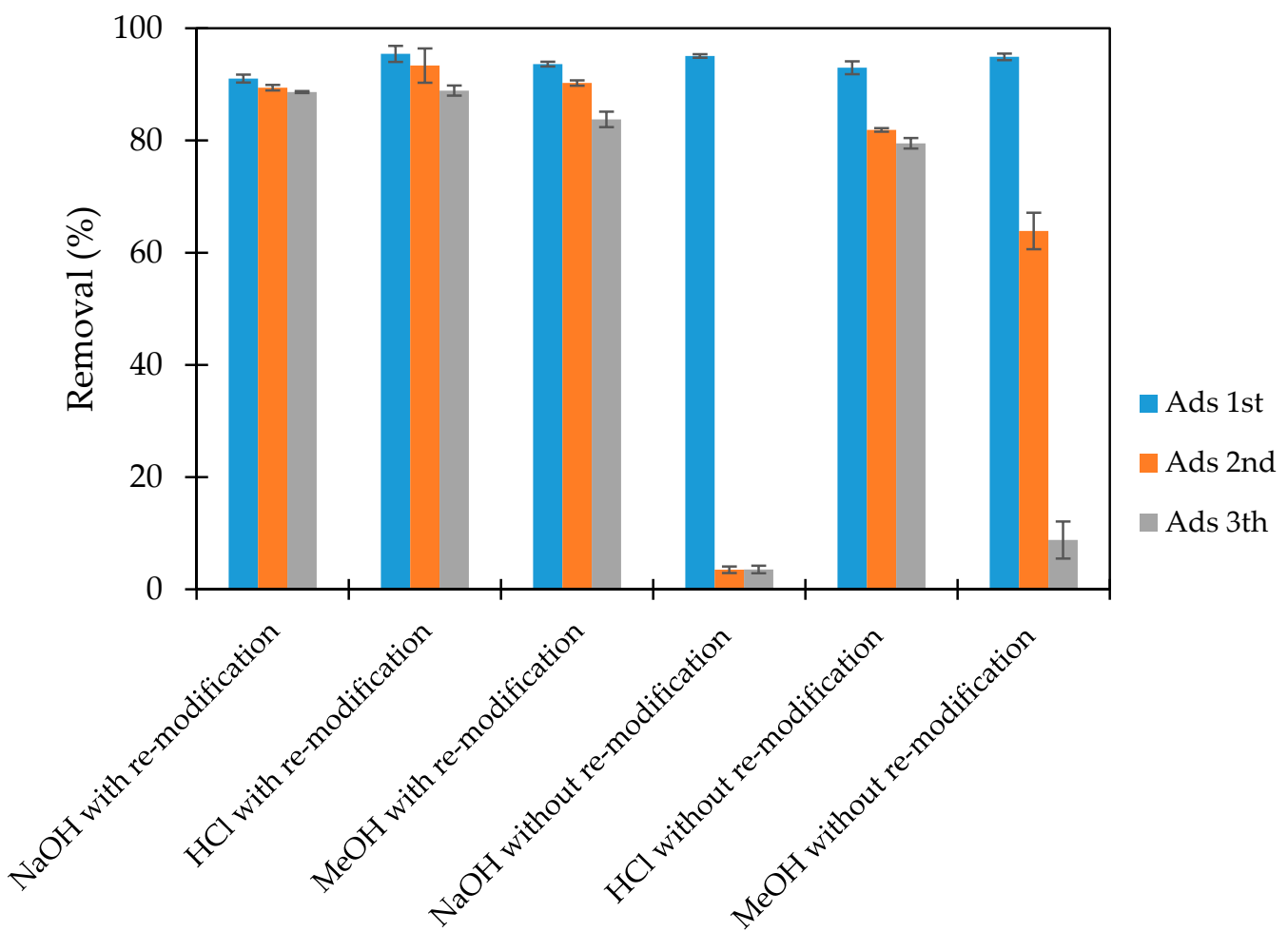

Figure 9. Regeneration of adsorbent with remodification and without remodification using different solutions $\mathrm{NaOH}, \mathrm{HCl}, \mathrm{MeOH}$. Error bars show standard deviation of three replicates.

\subsection{Application for CFX-Removal from Hospital Wastewater}

The optimum conditions for CFX-removal were applied for the treatment of an actual wastewater sample in this part. There are many complicated pollutants in real wastewater that strongly influences to performance of adsorbent. Therefore, the experimental evaluation of real sample treatment is important. Actual samples of wastewater were taken from a hospital in Hanoi. The wastewater samples were then kept stored at low temperature in a cooling refrigerator within 7 days of the experiment. Samples were pretreated by filtering to remove the tiny particles. As seen by the results, the optimum conditions for CFX-removal were obtained when the SMN dosage was kept at $5 \mathrm{mg} / \mathrm{mL}$ and the $\mathrm{pH}$ of wastewater was 7.0 (checked after pretreatment) and contact time $90 \mathrm{~min}$ for real sample a treatment application.

In this section, we try to remove CFX from the actual hospital wastewater. Figure 10 shows that the high background containing many contaminants in the UV spectra (A1) was significantly reduced after treatment with PMA, indicating that PMA can remove not only CFX, but also many contaminants that appear in wastewater. This trend is similar for the case of the addition of $5 \mathrm{mg} / \mathrm{L}$ of CFX into a real sample (A2). By calculations, the CFX-removal efficiency achieved greater than $75 \%$ when using PMA while only $30 \%$ of pollutant molecular was removed by using alumina without surface modification. Our results again indicate that PMA is a novel adsorbent and high performance for antibiotic removal from wastewater solution. 


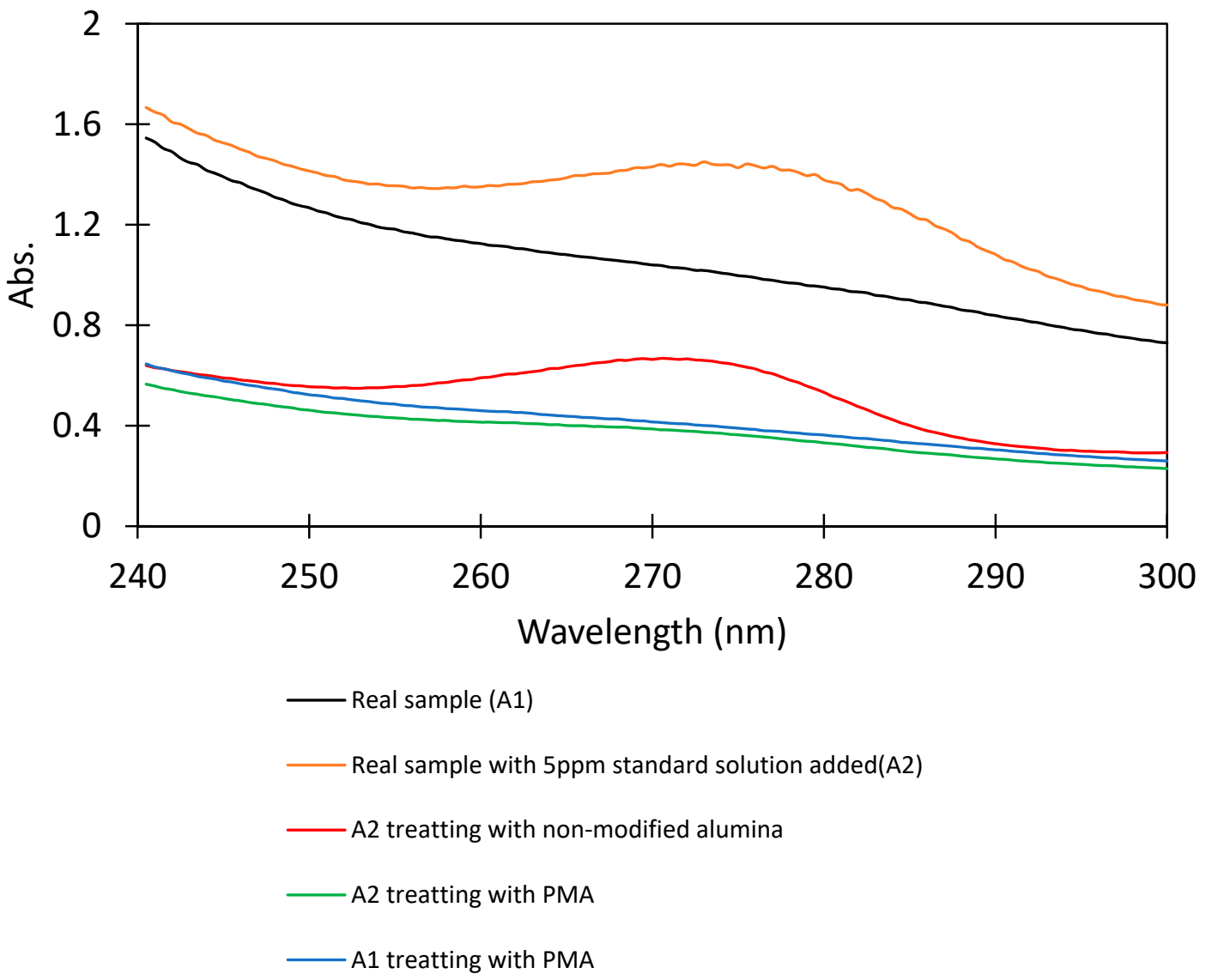

Figure 10. UV-Vis spectra of CFX in the hospital wastewater samples before and after treatment. The (A1) real sample and the (A2) real samples with 5 ppm of CFX standard solution added were treated using alumina and PMA. Baseline subtraction was conducted at the wavelength of CFX maximum absorbance, $272 \mathrm{~nm}$.

\section{Conclusions}

This paper reports a new study of PSS adsorption onto alumina particles and application in CFX-removal from water environment. The adsorption of PSS increased with increasing ionic strength due to the both electrostatic and non-electrostatic interactions and the adsorption capacity reached to $11.0 \mathrm{mg} / \mathrm{g}$. The removal of CFX achieved greater than $98 \%$ while the maximum adsorption capacity of $28.02 \mathrm{mg} / \mathrm{g}$ was achieved under the optimum conditions of $\mathrm{pH} 6$, contact time 90 and adsorption dosage of five milligrams per milliliter. The maximum CFX-adsorption capacity was found to be $25 \mathrm{mg} / \mathrm{g}$. The PMA was applicable for CFX-removal from an actual hospital wastewater with the removal efficiency of $75 \%$. Our results indicate that PSS adsorption plays a key role to form a novel adsorbent PMA for antibiotic removal from aqueous solution.

Author Contributions: Conceptualization, T.D.P. and D.B.L.; data curation, T.H.D. and N.T.N.; formal analysis, T.H.D., N.T.N. and C.L.N.; investigation, T.D.P. and D.B.L.; methodology, T.D.P. and M.N.N.; project administration, D.B.L.; resources, T.H.D. and N.T.N.; software, C.L.N and N.H.L.; supervision, T.D.P. and M.N.N.; validation, T.D.P and M.N.N.; visualization, T.D.P. and D.B.L.; writing-original draft, T.H.D., M.N.N., D.B.L and T.D.P; writing-review \& editing, T.H.D., D.B.L. and T.D.P. All authors have read and agreed to the published version of the manuscript.

Funding: This research is funded by Vietnam Academy of Science and Technology (VAST) under Grant Number TĐANQP.03/20-22.

Acknowledgments: Thi Huong Dao would like to thank to the financial support from the Vingroup Innovation Foundation and Toshiba Scholarships for Masters Course Study.

Conflicts of Interest: The authors declare no conflict of interest. 


\section{References}

1. Pendhari, S.S.; Kant, T.; Desai, Y.M. Application of polymer composites in civil construction: A general review. Compos. Struct. 2008, 84, 114-124. [CrossRef]

2. Huang, Z.-M.; Zhang, Y.-Z.; Kotaki, M.; Ramakrishna, S. A review on polymer nanofibers by electrospinning and their applications in nanocomposites. Compos. Sci. Technol. 2003, 63, 2223-2253. [CrossRef]

3. Kalia, S.; Kaith, B.; Kaur, I. Pretreatments of natural fibers and their application as reinforcing material in polymer composites-a review. Polym. Eng. Sci. 2009, 49, 1253-1272. [CrossRef]

4. Lisuzzo, L.; Cavallaro, G.; Milioto, S.; Lazzara, G. Layered composite based on halloysite and natural polymers: A carrier for the $\mathrm{pH}$ controlled release of drugs. New J. Chem. 2019, 43, 10887-10893. [CrossRef]

5. Bertolino, V.; Cavallaro, G.; Lazzara, G.; Milioto, S.; Parisi, F. Biopolymer-Targeted Adsorption onto Halloysite Nanotubes in Aqueous Media. Langmuir ACS J. Surf. Colloids 2017, 33, 3317-3323. [CrossRef]

6. Nguyen, N.T.; Dao, T.H.; Truong, T.T.; Nguyen, T.M.T.; Pham, T.D. Adsorption characteristic of ciprofloxacin antibiotic onto synthesized alpha alumina nanoparticles with surface modification by polyanion. J. Mol. Liq. 2020, 309, 113150. [CrossRef]

7. Zaman, S.B.; Hussain, M.A.; Nye, R.; Mehta, V.; Mamun, K.T.; Hossain, N. A review on antibiotic resistance: Alarm bells are ringing. Cureus 2017, 9. [CrossRef]

8. Walsh, T.R.; Efthimiou, J.; Dréno, B. Systematic review of antibiotic resistance in acne: An increasing topical and oral threat. Lancet Infect. Dis. 2016, 16, e23-e33. [CrossRef]

9. Chatterjee, A.; Modarai, M.; Naylor, N.R.; Boyd, S.E.; Atun, R.; Barlow, J.; Holmes, A.H.; Johnson, A.; Robotham, J.V. Quantifying drivers of antibiotic resistance in humans: A systematic review. Lancet Infect. Dis. 2018, 18, e368-e378. [CrossRef]

10. Yang, Y.; Song, W.; Lin, H.; Wang, W.; Du, L.; Xing, W. Antibiotics and antibiotic resistance genes in global lakes: A review and meta-analysis. Environ. Int. 2018, 116, 60-73. [CrossRef]

11. Yahya, M.S.; Oturan, N.; El Kacemi, K.; El Karbane, M.; Aravindakumar, C.; Oturan, M.A. Oxidative degradation study on antimicrobial agent ciprofloxacin by electro-Fenton process: Kinetics and oxidation products. Chemosphere 2014, 117, 447-454. [CrossRef] [PubMed]

12. Trovo, A.G.; Nogueira, R.F.P.; Agüera, A.; Fernandez-Alba, A.R.; Malato, S. Degradation of the antibiotic amoxicillin by photo-Fenton process-chemical and toxicological assessment. Water Res. 2011, 45, 1394-1402. [CrossRef] [PubMed]

13. Galvin, S.; Boyle, F.; Hickey, P.; Vellinga, A.; Morris, D.; Cormican, M. Enumeration and characterization of antimicrobial-resistant Escherichia coli bacteria in effluent from municipal, hospital, and secondary treatment facility sources. Appl. Environ. Microbiol. 2010, 76, 4772-4779. [CrossRef] [PubMed]

14. Bautitz, I.R.; Nogueira, R.F.P. Degradation of tetracycline by photo-Fenton process-Solar irradiation and matrix effects. J. Photochem. Photobiol. A Chem. 2007, 187, 33-39. [CrossRef]

15. Elmolla, E.; Chaudhuri, M. Optimization of Fenton process for treatment of amoxicillin, ampicillin and cloxacillin antibiotics in aqueous solution. J. Hazard. Mater. 2009, 170, 666-672. [CrossRef]

16. Dao, T.H.; Tran, T.T.; Nguyen, V.R.; Pham, T.N.M.; Vu, C.M.; Pham, T.D. Removal of antibiotic from aqueous solution using synthesized TiO 2 nanoparticles: Characteristics and mechanisms. Environ. Earth Sci. 2018, 77, 359. [CrossRef]

17. Chu, T.P.M.; Nguyen, N.T.; Vu, T.L.; Dao, T.H.; Dinh, L.C.; Nguyen, H.L.; Hoang, T.H.; Le, T.S.; Pham, T.D. Synthesis, Characterization, and Modification of Alumina Nanoparticles for Cationic Dye Removal. Materials 2019, 12, 450. [CrossRef]

18. Pham, T.D.; Tran, T.T.; Le, V.A.; Pham, T.T.; Dao, T.H.; Le, T.S. Adsorption characteristics of molecular oxytetracycline onto alumina particles: The role of surface modification with an anionic surfactant. J. Mol. Liq. 2019, 287, 110900. [CrossRef]

19. Pham, T.D.; Do, T.U.; Pham, T.T.; Nguyen, T.A.H.; Nguyen, T.K.T.; Vu, N.D.; Le, T.S.; Vu, C.M.; Kobayashi, M. Adsorption of poly (styrenesulfonate) onto different-sized alumina particles: Characteristics and mechanisms. Colloid Polym. Sci. 2019, 297, 13-22. [CrossRef]

20. Zhang, C.-L.; Qiao, G.-L.; Zhao, F.; Wang, Y. Thermodynamic and kinetic parameters of ciprofloxacin adsorption onto modified coal fly ash from aqueous solution. J. Mol. Liq. 2011, 163, 53-56. [CrossRef] 
21. Li, M.-F.; Liu, Y.-G.; Liu, S.-B.; Zeng, G.-M.; Hu, X.-J.; Tan, X.-F.; Jiang, L.-H.; Liu, N.; Wen, J.; Liu, X.-H. Performance of magnetic graphene oxide/diethylenetriaminepentaacetic acid nanocomposite for the tetracycline and ciprofloxacin adsorption in single and binary systems. J. Colloid Interface Sci. 2018, 521, 150-159. [CrossRef]

22. Zhu, B.-Y.; Gu, T. Surfactant adsorption at solid-liquid interfaces. Adv. Colloid Interface Sci. 1991, 37, 1-32. [CrossRef]

23. Pham, T.D.; Pham, T.T.; Phan, M.N.; Ngo, T.M.V.; Dang, V.D.; Vu, C.M. Adsorption characteristics of anionic surfactant onto laterite soil with differently charged surfaces and application for cationic dye removal. J. Mol. Liq. 2020, 301, 112456. [CrossRef]

24. Pham, T.D.; Kobayashi, M.; Adachi, Y. Adsorption of anionic surfactant sodium dodecyl sulfate onto alpha alumina with small surface area. Colloid Polym. Sci. 2015, 293, 217-227. [CrossRef]

25. Pham, T.D.; Vu, T.N.; Nguyen, H.L.; Le, P.H.P.; Hoang, T.S. Adsorptive Removal of Antibiotic Ciprofloxacin from Aqueous Solution Using Protein-Modified Nanosilica. Polymers 2020, 12, 57. [CrossRef] [PubMed]

26. Pham, T.D.; Kobayashi, M.; Adachi, Y. Adsorption of Polyanion onto Large Alpha Alumina Beads with Variably Charged Surface. Adv. Phys. Chem. 2014, 2014, 9. [CrossRef]

27. Mészáros, R.; Thompson, L.; Bos, M.; de Groot, P. Adsorption and Electrokinetic Properties of Polyethylenimine on Silica Surfaces. Langmuir 2002, 18, 6164-6169. [CrossRef]

28. Adamczyk, Z.; Zembala, M.; Warszyński, P.; Jachimska, B. Characterization of Polyelectrolyte Multilayers by the Streaming Potential Method. Langmuir 2004, 20, 10517-10525. [CrossRef]

29. Guzmán, E.; Cavallo, J.A.; Chuliá-Jordán, R.; Gómez, C.; Strumia, M.C.; Ortega, F.; Rubio, R.G. pH-Induced Changes in the Fabrication of Multilayers of Poly(acrylic acid) and Chitosan: Fabrication, Properties, and Tests as a Drug Storage and Delivery System. Langmuir 2011, 27, 6836-6845. [CrossRef]

30. Guzman, E.; Ritacco, H.; Rubio, J.E.F.; Rubio, R.G.; Ortega, F. Salt-induced changes in the growth of polyelectrolyte layers of poly(diallyl-dimethylammonium chloride) and poly(4-styrene sulfonate of sodium). Soft Matter 2009, 5, 2130-2142. [CrossRef]

31. Hoffmann, I.; Oppel, C.; Gernert, U.; Barreleiro, P.; von Rybinski, W.; Gradzielski, M. Adsorption Isotherms of Cellulose-Based Polymers onto Cotton Fibers Determined by Means of a Direct Method of Fluorescence Spectroscopy. Langmuir 2012, 28, 7695-7703. [CrossRef] [PubMed]

32. Moujahid, E.M.; Inacio, J.; Besse, J.-P.; Leroux, F. Adsorption of styrene sulfonate vs. polystyrene sulfonate on layered double hydroxides. Microporous Mesoporous Mater. 2003, 57, 37-46. [CrossRef]

33. Duman, O.; Tunç, S.; Çetinkaya, A. Electrokinetic and rheological properties of kaolinite in poly (diallyldimethylammonium chloride), poly (sodium 4-styrene sulfonate) and poly (vinyl alcohol) solutions. Colloids Surf. A Physicochem. Eng. Asp. 2012, 394, 23-32. [CrossRef]

34. Genç, N.; Dogan, E.C. Adsorption kinetics of the antibiotic ciprofloxacin on bentonite, activated carbon, zeolite, and pumice. Desalin. Water Treat. 2015, 53, 785-793. [CrossRef]

35. El-Shafey, E.-S.I.; Al-Lawati, H.; Al-Sumri, A.S. Ciprofloxacin adsorption from aqueous solution onto chemically prepared carbon from date palm leaflets. J. Environ. Sci. 2012, 24, 1579-1586. [CrossRef]

36. Aloulou, F.; Boufi, S.; Beneventi, D. Adsorption of organic compounds onto polyelectrolyte immobilized-surfactant aggregates on cellulosic fibers. J. Colloid Interface Sci. 2004, 280, 350-358. [CrossRef]

37. Pham, T.; Bui, T.; Nguyen, V.; Bui, T.; Tran, T.; Phan, Q.; Hoang, T. Adsorption of polyelectrolyte onto nanosilica synthesized from rice husk: Characteristics, mechanisms, and application for antibiotic removal. Polymers 2018, 10, 220. [CrossRef] [PubMed]

38. Pham, T.D.; Nguyen, H.H.; Nguyen, N.V.; Vu, T.T.; Pham, T.N.M.; Doan, T.H.Y.; Nguyen, M.H.; Ngo, T.M.V. Adsorptive removal of copper by using surfactant modified laterite soil. J. Chem. 2017, 2017. [CrossRef]

(C) 2020 by the authors. Licensee MDPI, Basel, Switzerland. This article is an open access article distributed under the terms and conditions of the Creative Commons Attribution (CC BY) license (http://creativecommons.org/licenses/by/4.0/). 